\title{
CURSO DE ARQUIVOLOGIA DA UEL: CONSOLIDAÇÃO DE UMA PROPOSTA DE PARCERIA
}

\author{
MARY STELA MULLER (Coord.) \\ MARTA LÍGIA POMIM VALENTIM \\ LICÉIA CIANCA FORTES \\ Departamento de Ciências da Informação \\ CLAUDIOMAR DOS REIS GONĢALVES \\ CRISTIANO GUSTAVO BIAZZO SIMON \\ ROSIMEIRE APARECIDA ANGELINI CASTRO \\ Departamento de História
}

\begin{abstract}
Resumo
Projeto de implantação do curso de Arquivologia na Universidade Estadual de Londrina, incluindo pesquisa prévia sobre mercado e clientela na região. Inovação na proposta de trabalho em parceria: o Departamento de Ciências da Informação e o Departamento de História. Currículo pretende obter um profissional com base humanística e técnica, visando o moderno profissional da informação para o século XXI. Apresenta também ementas, objetivos e conteúdos de todas as disciplinas do curso.

Palavras-Chave

Arquivologia. Profissional da informação. Mercado de trabalho. Curso de Arquivologia.
\end{abstract}

Introdução

O entendimento de proposta curricular como uma estrutura que se constrói para responder a interesses determinados e não como uma organização neutra de disciplinas integradas é que norteou a proposta que ora se apresenta.
A nova ordem mundial reclama um profissional diferenciado e competente que, para tanto, deve caracterizar-se por demonstrar formação científica e capacidade de adaptação às novas relações econômico-sociais. Enfim, um novo perfil, no qual seja contemplada uma capacidade empresarial para "a venda" de seus serviços e uma capacidade inovadora e criativa 
para ir ao encontro do que demandará a sociedade do século XXI.

O conjunto de avanços tecnológicos da terceira revolução da ciência e tecnologia requer mão-de-obra inteligente e capaz de relacionar-se com esses avanços que têm invadido o mercado nas últimas décadas.

No chamado setor quaternário da economia, o trabalho intelectual do profissional da informação, neste caso, arquivologia, deve desenvolver diferentes capacidades de produtividade ao dispor das novas ferramentas, dos processos e dos produtos da indústria do conhecimento, estabelecendo assim outros perfis desse profissional, antes desconhecidos e impensados.

$\mathrm{Na}$ busca de tal profissional, fez-se necessária uma oferta educativa que permitisse as relações existentes entre as diversas áreas que conformam a Arquivologia, a partir da parceria dos departamentos de Ciência da Informação e de História, com a contribuição de vários outros departamentos, consubstanciada na interdisciplinaridade e em conformidade com a legislação vigente. O presente currículo orientou-se para a formação de profissionais de Arquivologia, de acordo com o manejo das abstrações dos novos processos lógico-lingüísticos, assim como da aplicação das tecnologias disponíveis. Orienta-se também para a compreensão e utilização da linguagem da ciência a fim de colocar essas habilidades a serviço da preservação e organização necessárias à disponibilização social da memória e da informação arquivística.

\section{Justificativa}

Desde o século XVIII, assistiu-se na Europa a criação de arquivos nacionais. Esta política pretendeu ordenar a publicidade dos arquivos e disponibilizar os documentos da memória nacional. As comemorações revolucionárias, especialmente francesas, apropriaram-se de novos instrumentos de suporte — objetos materiais — para possibilitar a comemoração do passado. No século XIX, houve a criação de instituições especializadas, com a finalidade de formar especialistas para o estudo dos fundos documentais. O arquivista tinha uma função primordial não só nos Arquivos Nacionais, como também em Museus, Bibliotecas, nas escolas de Paleografia e Diplomática e, como herança da Idade Média, nas instituições Eclesiásticas.

No caso brasileiro, a formação do Estado Imperial resultou em um relacionamento entre o setor político e a sociedade civil, que diferenciou de maneira nítida a esfera pública do setor privado. A ênfase do direito público foi dada para o princípio organizacional de todo o ordenamento político. Em decorrência, os vários setores públicos geraram uma farta produção documental, que acelerou princípios do Estado Republicano. O próprio Arquivo Nacional, órgão máximo da arquivística brasileira, foi criado na primeira metade do século XIX e teve como função principal a de ser o guardião da Memória Nacional.

No século XX, vários arquivos vieram a ser fundados. Contudo, enquanto em outros 
países, até a década de 50, o que prevaleceu era a existência dos chamados "Archvists", ou melhor, administradores de documentos, no Brasil e na América Latina, "perdurou a tradição de maior peso dos arquivistas-historiadores na área profissional" (Bellotto, 1990, p.40).

O crescimento substancial de arquivos após a década de 50, principalmente com a criação do Conselho Internacional de Arquivos, procurou a união completa da profissão arquivística. Entretanto, a partir desse momento "reconheciase que o trabalho nos arquivos correntes e nos arquivos permanentes tinha ênfases diferentes" (Bellotto, 1990, p.40).

Passados os anos da influência tecnicista americana e com as transformações ocorridas em termos mundiais - na década de 80 e princípios dos anos 90 - pôde-se verificar o alargamento da noção de documento e arquivo. Atualmente, os arquivos não são formados apenas por textos, ou seja, "documentos providos de sintaxe, continuidade narrativa e coerência discursiva" como argumenta Camargo, o arquivo não é apenas o local onde se armazena com exclusividade o papel, tradicional suporte do texto. Terá que lidar com outros sistemas registro óptico sobre película cinematográfica... registro de imagem e som sobre fita magnética, holografia etc. (1989, p.7). Saliente-se as mudanças e inovações operadas nas técnicas de comunicação mais recentes.

A despeito disso, a antiga função de constituição do arquivo e do arquivista ainda permanece, qual seja, a função de "transmitir ao futuro a memória de nosso tempo, da mesma forma que a memória do passado nos foi transmitida", conforme ensina Duchein (1978, p.32). Não obstante, a atualidade impõe à área de Arquivologia uma nova problemática: a de se entender "o arquivo" não apenas como aquela instituição capaz e necessária à conservação, estudo e transmissão da memória, mas ainda a de absorver a expansão do conceito de documento, ocorrido nas últimas décadas e, por conseqüência, o alargamento da noção de Arquivo, que redefine o campo de trabalho arquivístico.

Logo o arquivista não pode ser confundido com os "archvists" de décadas anteriores, porquanto deve atuar não apenas em instituições públicas, mas em vários setores da sociedade, públicos ou privados, nos quais o gerenciamento de sistemas arquivísticos, quer sejam de particulares, de grupos, empresas, indústrias etc., se faça necessário. Por essa razão o atual profissional necessita receber uma formação fundamentalmente inter e multidisciplinar, no que tange aos vários aspectos da sociedade: sua constituição, permanência e transformação em suas micro e macro esferas (Camargo, 1989, p.9).

Mediante esse contexto e face às necessidades atuais e futuras do mercado, a quantidade de ofertas de cursos no Brasil é insuficiente (Bottino, 1994, p.17). Leve-se em consideração que os cursos implantados e em funcionamento não conseguem atender à demanda quantitativa de instituições públicas e privadas brasileiras. Além disso, elas necessitam de profissionais que auxiliem na agilização da 
administração, e que possuam uma formação humanística, que possa dotá-los de habilidades para gerenciamento e preservação do patrimônio documental.

Embora a colonização da região norte do Paraná seja historicamente recente, é perceptível uma profusão de instituições públicas e particulares que carecem de profissionais que atuem na organização e preservação de seus arquivos documentais. Além da necessidade de acesso à informação dos arquivos correntes e intermediários, que racionalizam a administração, há um evidente interesse em acessar a informação nos arquivos permanentes como fonte de investigação e pesquisa.

Empresas, clínicas médicas, escritórios de advocacia e contabilidade são alguns dos representantes das entidades privadas. Além destas, outras que se constituíram a partir dos movimentos sociais como, por exemplo, os sindicatos, partidos políticos, associações profissionais, além das igrejas em geral, apresentam uma preocupação com o tratamento de informações arquivísticas e, conseqüentemente, com a memória e a identidade dessas associações civis.

Escolas públicas e privadas, bibliotecas, museus, centros de documentação, órgãos das administrações das Faculdades e Universidades, dos municípios e sobretudo do Estado, precisam ter um atendimento eficiente para melhorar o desempenho da própria instituição, bem como satisfazer melhor o seu público: o cidadão e o pesquisador.
Sabe-se que a partir dos anos 60, o Brasil experimentou, seguindo uma tendência mundial, uma profusão incrível na sua produção documental. Mais recentemente, vivência as grandes transformações provocadas pelo advento da informática. O Estado do Paraná e seus vizinhos - São Paulo, Mato Grosso, Santa Catarina - fatualmente ampliaram e adequaram suas instituições e produziram conjuntos documentais acumulados em variados suportes. Quem se encarrega de organizar essa massa documental e agilizar a informação de forma adequada? Certamente não é profissional formado em Arquivologia capaz de realizar serviços que transcendam o trabalho técnico e simplificador.

Afirma Oliveira (1992) que a necessidade do acesso cada vez mais rápido à informação, tanto pelo produtor do documento usuário interno, como pelo usuário externo; que o vertiginoso crescimento da produção documental; que a mudança do perfil do pesquisador o qual freqüentemente solicita informações contidas em conjuntos documentais homogêneos e a quem foi não interessa um documento isolado, um fato, ou um acontecimento individualizado a não ser para efeitos da prova, isto é, na comprovação de direitos, são características que atestam a complexidade do trabalho arquivístico, que exige contínuo aperfeiçoamento e atualização dos profissionais da área.

Para tanto, o arquivista deverá ser capaz de gerenciar os arquivos, garantindo que os documentos sejam transferidos para suas diferentes idades, utilizando-se de metodologia 
científica adequada a sua diversidade. Além disso, deverá observar quando da seleção dos documentos e necessária interação com profissionais de outras áreas envolvidos na fase de produção documental e/ou com conhecimentos jurídicos, os critérios para guarda e descarte.

Tais aspectos, por si só justificam a importância da criação e consolidação do primeiro curso de graduação em Arquivologia no Paraná, considerando-se não apenas o crescente desenvolvimento da região como também a sua vinculação política e econômica ao Mercosul.

\section{Princípios Norteadores do Projeto Pedagógico do Curso}

No Brasil, os Arquivos Públicos contribuíram sobremaneira para a consolidação de uma tradição de trabalho arquivístico. No entanto, não foram o bastante suficientes para suportar a formação de um corpo teórico/técnico que atuasse nas diferentes instituições arquivísticas.

Segundo Camargo, "a tradição positivista, que marca a historiografia do século XIX, não significou para os pesquisadores, como poderia parecer à primeira vista, a valorização do documento ou do arquivo público", ao menos no Brasil. Este quadro afetou de forma significativa o desenvolvimento posterior das ciências ligadas ao estudo e à preservação da memória. Belloto (1990, p.40) afirma que, até meados do século XX, "assistiu-se à extrema valorização do arquivista historiador, erudito, paleógrafo e diplomacista, mais voltado para o documento em si do que para as instâncias administrativas de onde ele provinha".

A grande profusão da produção documental, e a própria expansão do conceito de documento, tornaram imprescindível e indispensável a formação de um profissional que não somente esteja voltado para as técnicas da arquivística, mas que também possua amplos conhecimentos sobre: gestão de arquivos, métodos da pesquisa histórica, novas tecnologias de preservação, além de outros.

Mediante o alargamento do conceito de documento, os novos interesses, as novas abordagens historiográficas, é que se impõe uma revisão da concepção de arquivos e se faz necessária uma reflexão maior a respeito do profissional que os cursos de graduação pretendem formar.

Quanto à concepção do que vem a ser um profissional de arquivo, é relevante considerar que $o$ arquivista não pode ser um mero reprodutor e manipulador de técnicas, embora deva dominálas. Este profissional, obrigatoriamente, precisa ter uma formação humanística, que lhe permita desenvolver reflexões de cunho teórico, a exemplo de uma postura crítica frente à problemática arquivística e suas interfaces com a documentação: a reflexão sobre seu uso, manipulação, e sua relação com as demais instituições ligadas à arquivística brasileira.

Assim, a concepção que embasa a criação deste curso é a íntima e indissolúvel vinculação entre o conhecimento prático e teórico. Essa 
integração é vital para o bom desempenho da prática arquivística, seja nos arquivos públicos ou privados, seja nas diferentes idades ou fases dos mesmos: corrente, intermediário e permanente. As disciplinas foram dispostas na grade curricular de forma a garantir o entrelaçamento entre ensino e pesquisa, possibilitando a construção do conhecimento arquivístico.

Da leitura do currículo mínimo proposto pelo Conselho Federal de Educação, apreendese que sua concepção foi norteada por dois princípios: $1^{\circ} \mathrm{o}$ atendimento prioritário à formação de profissionais para arquivos permanentes, que contemplava a demanda existente à época da criação do curso em decorrência do acelerado crescimento da burocracia brasileira; $2^{\circ} \mathrm{o}$ aproveitamento da estrutura universitária e de seu corpo docente, originário de áreas afins à arquivologia (Monteiro, 1988, p.82).

A partir dessa constatação, o curso de graduação em Arquivologia da UEL será desenvolvido pelos departamentos de Ciências da Informação e História, em parceria, e com a colaboração de vários outros departamentos da instituição, no intuito de garantir uma formação que dê suportes técnicos ao futuro profissional e que o capacite a avaliar, selecionar e preservar documentos, embasado em conhecimentos teóricos, aliados à pesquisa.

Esse profissional que entrará no mercado, já beneficiado por uma carreira regulamentada, poderá atuar nas instituições e órgãos públicos, uma vez que existe premência por parte de
Estados e Municípios de modernizar seus arquivos. Além disso, estará habilitado para trabalhar em uma diversidade de locais que necessitam de um profissional capacitado em Arquivologia: arquivos dos poderes públicos (executivo, legislativo e judiciário), arquivos empresariais, arquivos eclesiásticos, escolares, médicos, além, logicamente, das instituições consagradas à documentação: Bibliotecas, Arquivos públicos estaduais e municipais, centros de documentação, museu, etc. Enfim, atuarão em todas essas instituições, proprietárias de um valioso patrimônio documental que, uma vez organizado e norteado pelo princípio do respeito aos fundos (Bellotto, 1991), permitirá um melhor conhecimento da sociedade loco regional e brasileira, com informações relevantes em termos econômicos, históricos, sociológicos e antropológicos, entre outros.

\section{Objetivos do Curso}

Mediante o exposto estabeleceu-se os seguintes objetivos à consolidação do Curso de Arquivologia da UEL:

- Formar recursos humanos para o desempenho da prática arquivística em arquivos públicos e privados;

- Formar profissionais para atuar nas regiões Sul, Sudeste e Centro-Oeste do país, visando atender a uma demanda social em relação à preservação da memória de instituições públicas e privadas;

- Promover mudanças na concepção do ensino tradicional da arquivologia no 
Brasil, capacitando profissionais para a administração de arquivos nas suas diferentes idades;

- Fornecer embasamento para o reconhecimento e leitura de fundos documentais diversos;

- Fornecer os conhecimentos básicos para situar a problemática arquivística nos contextos econômico - produtivo comercial e histórico de organizações públicas e privadas.

\section{Pesquisa de Mercado e de Clientela}

Para implementação do curso de Arquivologia na UEL, inicialmente, foi elaborado dois instrumentos de pesquisa: um voltado para o mercado empregador e outro voltado para a clientela do curso, ou seja, alunos de $2^{\circ}$ grau.

$\mathrm{Na}$ consulta ao mercado empregador, foi elaborado um questionário e enviado à administração pública e privada do Estado do Paraná. Para a administração pública direta, todos os órgãos governamentais, ligados ao executivo, legislativo e judiciário, já para a administração pública indireta, instituições de economia mista, institutos de pesquisa etc.

$\mathrm{Na}$ administração privada, foram selecionadas organizações ligadas a vários segmentos econômicos como a área jurídica, contábil, médica, sindicatos e associações de classe, entre outras.

A primeira questão verificada foi em relação a existência formal de arquivos nas organizações, visando um mapeamento da situação dos arquivos nessas organizações (Gráfico 1), uma vez que partiu-se da hipótese de que os arquivos na sua grande maioria não existem formalmente no organograma da organização, dificultando a contratação de um profissional capacitado para desempenhar a

GRÁFICO 1

Exis te na Estrutura Organizacional um Setor de Arquivos?
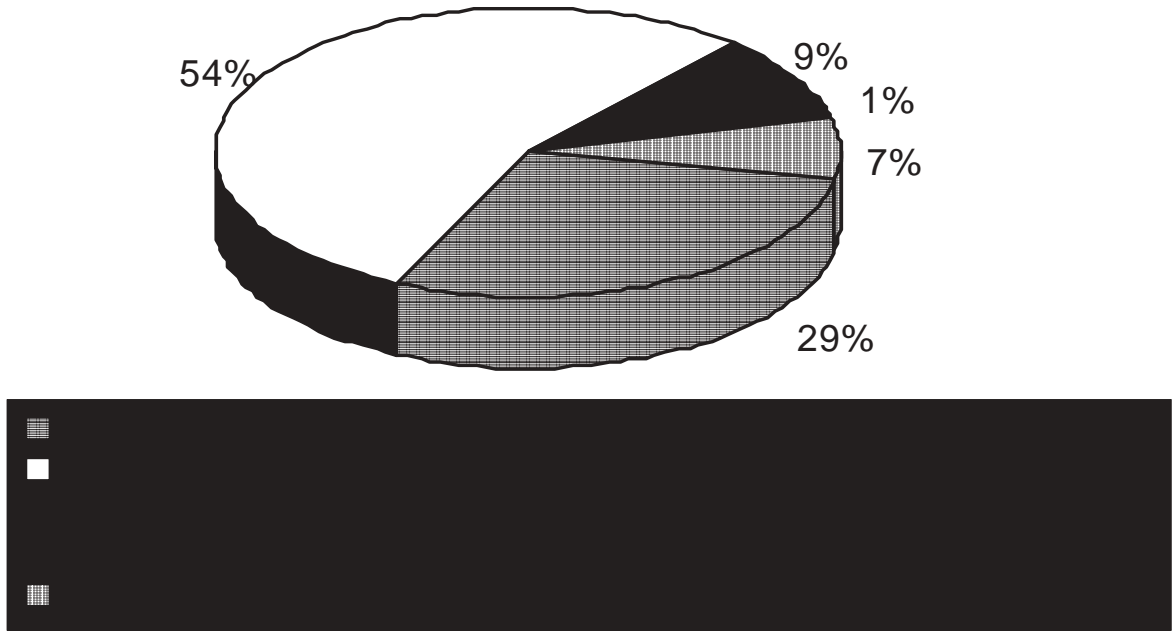
função de arquivista, consolidando, portanto, sua necessidade dentro das organizações, quer sejam públicas ou privadas.

A hipótese foi confirmada através da pesquisa, porque somente $29 \%$ das organizações pesquisadas tinham o setor de arquivos no organograma da organização contra $54 \%$ que afirmaram que o setor de arquivos não consta formalmente na estrutura organizacional.

Os pesquisados foram unânimes $(90 \%)$ em relação a importância atribuída aos arquivos (Gráfico 2) dentro das organizações.

\section{GRÁFICO 2}

Qual a Im portância Atribuída ao Setor de Arquivos?
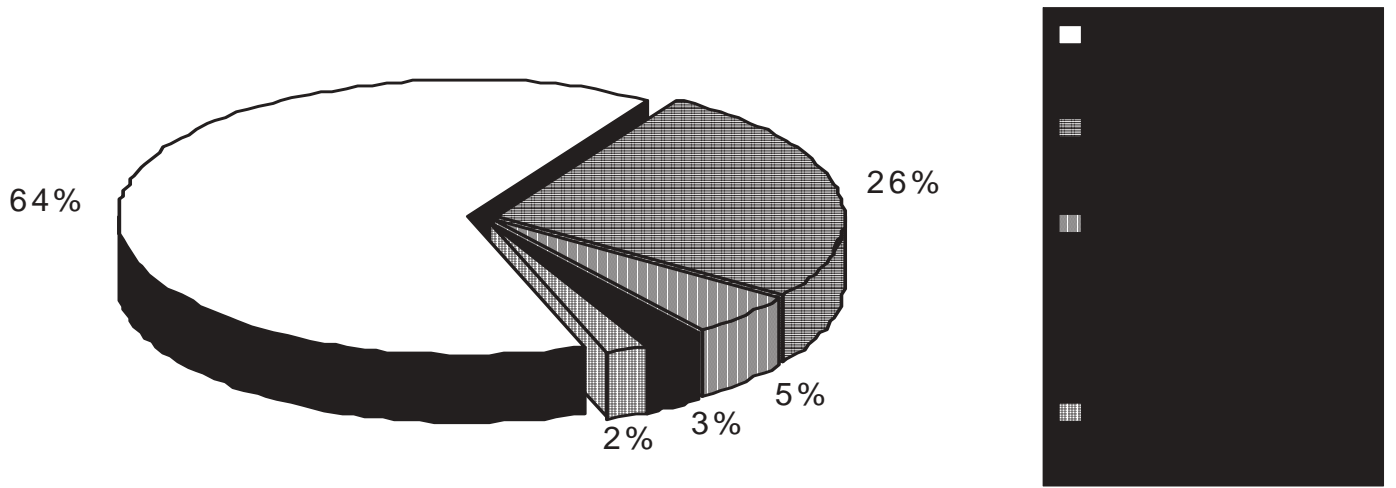

Outra questão pesquisada foi em relação as necessidades informacionais atendidas pelo setor de arquivos da organização (Gráfico 3), onde 53 entrevistados responderam que não estão satisfeitos com o atendimento, consolidando uma vez mais a necessidade de contratação de um profissional capacitado para exercer esta função.

Gráfico 3

\section{O Gerenciamento do Sistem a de Arquivo Atende as Necessidades da Organizaçã o?}
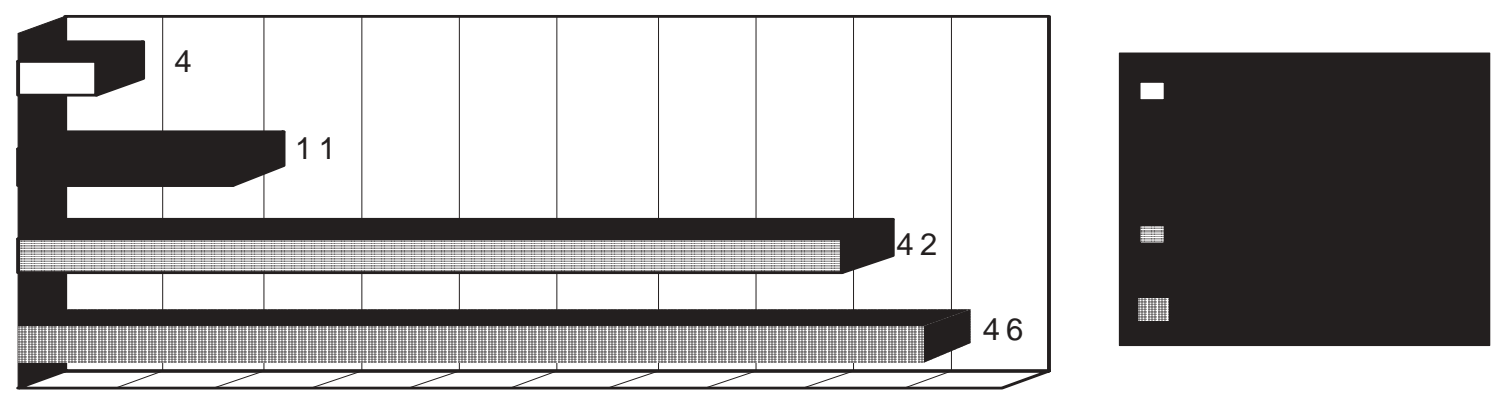
Em relação a funcionários especificamente no setor de arquivos, a maioria $76 \%$, ou não contratados para atuar no setor de arquivos possuem funcionários para o setor de arquivo ou (Gráfico 4), apenas 17\% dos pesquisados contratam funcionários que desempenham várias possuem funcionários exclusivamente para atuar funções inclusive a do arquivo.

\section{GRÁFICO 4}

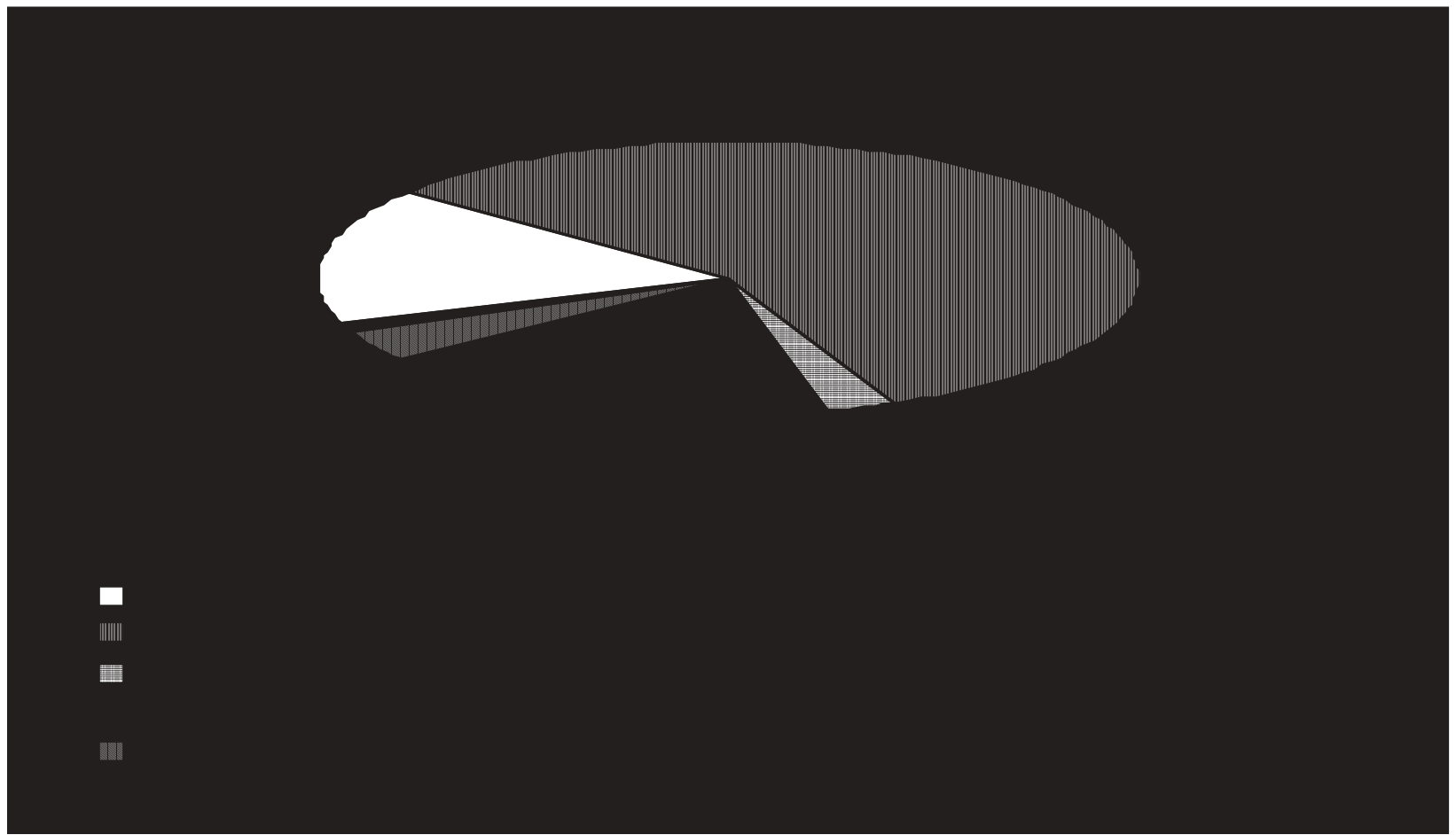

Entre os $17 \%$ que responderam que tinham a formação em arquivologia, o restante $88 \%$ funcionários específicos para o setor de arquivo, possuem formação em outras áreas do verificou-se qual a formação profissional dos conhecimento.

funcionários (Gráfico 5), destes apenas $12 \%$ têm

\section{GRÁFICO 5}

\section{Form a çã o}
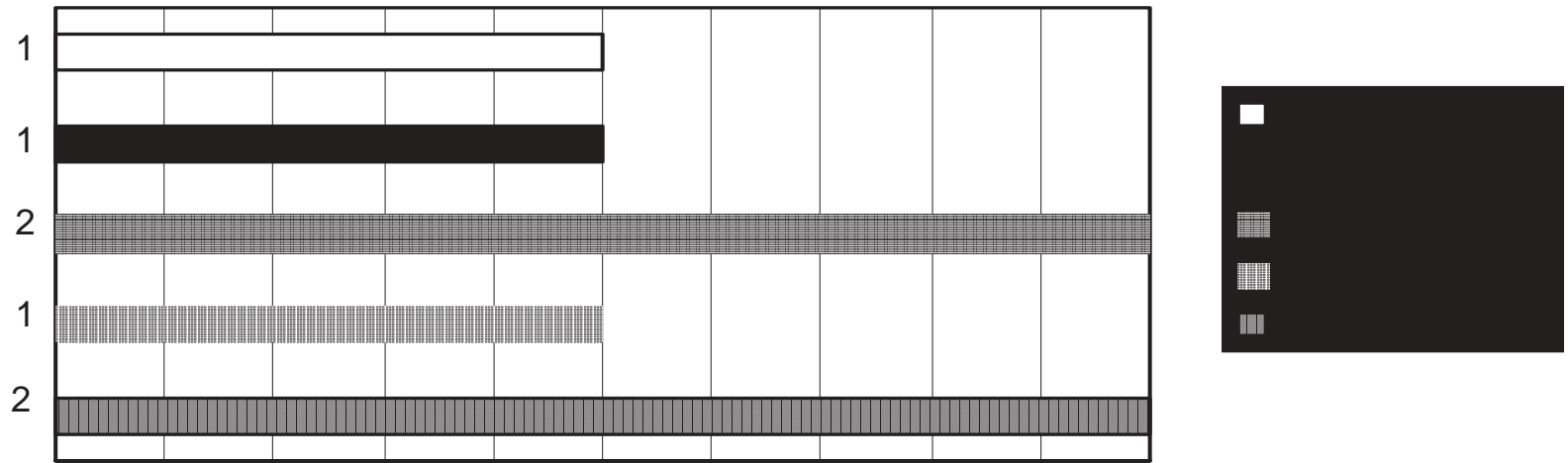
Dos pesquisados, 46 organizações (Gráfico 6) e (Gráfico 7) que o profissional responderam que contratariam um profissional formado poderá oferecer serviços de melhor com formação em arquivologia, justificando qualidade e maior eficiência.

\section{GRÁFICO 6}

GRÁFICO 7

Justificativa de Opinião
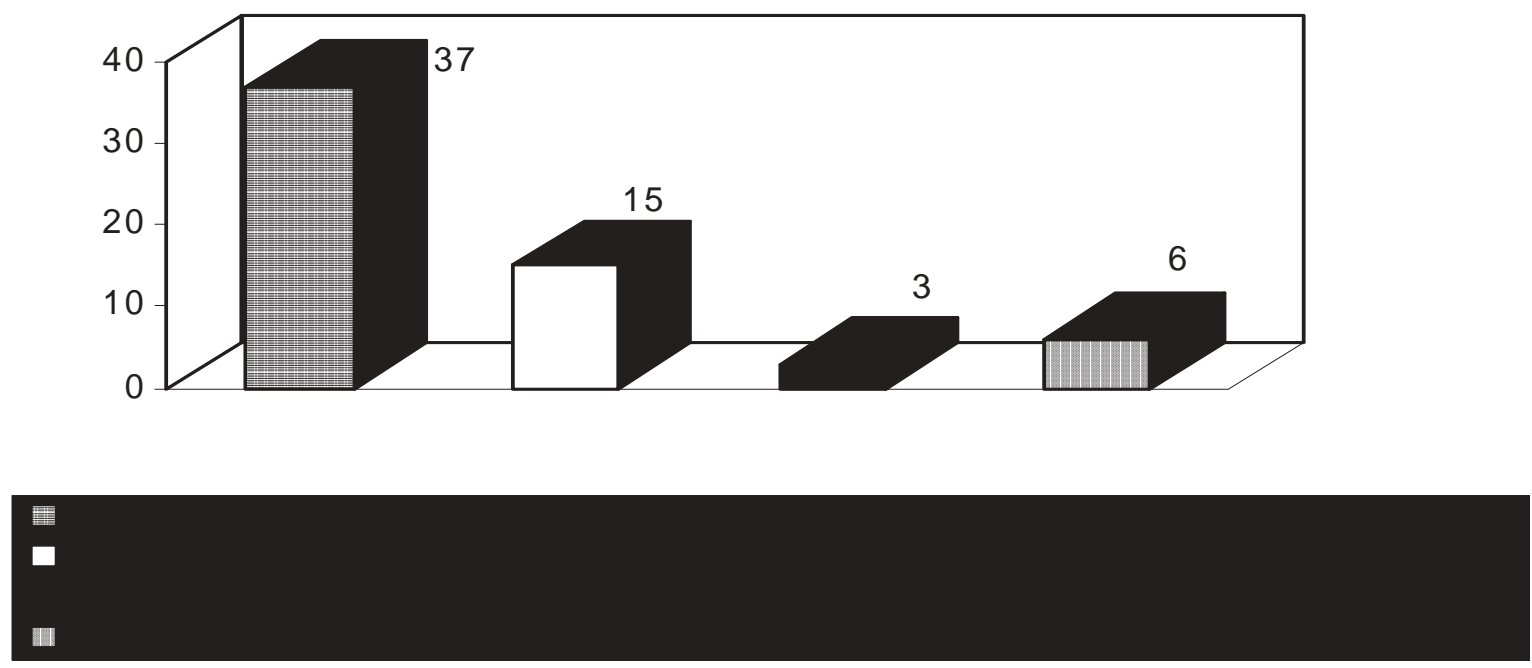

Para a pesquisa de clientela foi elaborado escola privada, o Colégio São José, escola do um questionário, visando verificar a demanda do sistema estadual de educação e o Colégio de curso de arquivologia. Foram selecionados três Aplicação, escola modelo, vinculada a escolas de $2^{\circ}$ grau, o Colégio Universitário, Universidade Estadual de Londrina. A população $54 \quad$ Inf.Inf., Londrina, v.2, n.1, p.45-66, jan./jun. 1997 
alvo entrevistada foi de um total de 983 alunos.

Houve unanimidade em relação aos alunos, 880 alunos, quanto a se cursariam graduação em arquivologia, apenas 103 disseram que não cursariam.

Quanto ao conceito e imagem, bem como as funções e atividades da profissão de arquivista, apenas 228 alunos demonstraram saber ou conhecer a profissão e seu mercado de trabalho, a grande maioria ainda desconhece a área, a profissão e o mercado de trabalho.

Em relação ao período que o curso deveria ser oferecido, a maioria, 548 alunos, sugeriu o período noturno.

\section{Perfil do Profissional que o Curso pretende formar}

A profissão de arquivista, como todas as outras profissões, tem sido submetida a uma evolução acelerada devido às mudanças da estrutura do conhecimento, às ocupações geradas pela revolução científica-tecnológica, assim como pelas constantes mudanças políticas, econômicas e culturais da sociedade.

A evolução da tecnologia tem influenciado particularmente as atividades desenvolvidas pelos arquivistas, obrigando as escolas-cursos a reverem seus currículos e repensarem o profissional que desejam formar.

As vertiginosas transformações que culminaram na globalização da economia mundial, os crescentes níveis de competitividade internacional, o alto valor agregado das tecnologias e o ingresso na era da informação estão propiciando uma nova restruturação do conhecimento, bem como requerendo a formação de recursos humanos de alto nível para responder aos desafios futuros.

Por outro lado, a informação precisa e oportuna constitui atualmente o insumo básico e fator de importância central nos diversos processos da atividade humana.

O mundo mudou e cresce na sociedade a conscientização da importância da informação e da memória, como fator de transformação e de alavanca para o desenvolvimento. No entanto, a nova ordem mundial exige um profissional mais comprometido com as "causas e coisas" da área e competente para enfrentar os novos desafios futuros.

O mercado exige, portanto, um profissional apto a trabalhar com a informação desde a produção, coleta, organização, interpretação, armazenamento, recuperação, disseminação e uso da mesma, utilizando como ferramenta a tecnologia disponível, porquanto a virtualidade dos registros documentais já consiste realidade.

Assim, numa atitude pró-ativa, norteados por uma visão estratégica, os departamentos de Ciências da Informação e História da Universidade Estadual de Londrina pretendem, com a criação desse curso e o conseqüente currículo proposto (Anexos 1, 2 e 3) o qual acredita-se inovador, propiciar ao profissional da arquivologia a consolidação de sua formação sob dois aspectos: 


\section{Formação humanística}

- que alicerce a consciência de sua responsabilidade social com a memória;

- que forneça embasamento para o reconhecimento e leitura de fundos documentais diversos, capacitando para a administração de arquivos nas suas diferentes idades;

- que forneça os conhecimentos básicos para situar a problemática arquivística nos contextos econômico-produtivo-comercial e histórico de organizações públicas e privadas.

\section{Formação técnica}

- que desenvolva habilidades e capacidades que o qualifiquem como e enquanto profissional, em termos de conhecimento e possibilidades de gerenciamento, empreendimento, estruturação de serviços, consultoria e assessoria, comunicação, promoção, marketing e redação de projetos;

- que propicie relacionar o manejo das abstrações de processos lógico - lingüísticos e a aplicação das tecnologias disponíveis para a compreensão e utilização da linguagem da ciência, possibilitando interagir e integrar-se com equipes multidisciplinares, colocando essas habilidades a serviço da preservação e organização necessárias à disponibilização social da memória e da informação.

\section{Considerações Finais}

A parceria que se consolida entre o Departamento de Ciências da Informação e o Departamento de História, pretende a interação e a interdisciplinaridade de áreas que se complementam numa práxis Arquivística.

No cotidiano dos Arquivos Públicos, profissionais Arquivistas e historiadores trabalham em parceria, promovendo e gerando produtos e serviços Arquivísticos de qualidade.

O curso de graduação em Arquivologia da UEL pretende oportunizar uma formação com enfoque nas áreas já mencionadas, formando assim um profissional com características próprias e inovadoras.

O Currículo (Anexos 1, 2 e 3) demonstra uma preocupação com a formação de um profissional moderno voltado para o "fazer" Arquivístico que os novos tempos requerem.

A preocupação em associar as tecnologias de informação com a organização, processamentos, produção, disseminação da documentação arquivística, bem como a otimização da gestão de sistemas Arquivísticos, exige uma educação teórico-prático compatível.

Neste sentido, o presente currículo pretende concretizar a partir da integração de conteúdos mínimos e objetivos fixados para as diferentes disciplinas, um projeto pedagógico que propicie aos futuros profissionais uma formação diferenciada que atenda aos diferentes segmentos de mercado.

\section{Bibliografia}

BELLOTTO, H. L. Formação profissional e ensino arquivístico. Arquivo Rio Claro, Rio Claro, São Paulo, v.9, n.2, p.37-48, jul. 1990. Identificação de fundos. IN: 
CASTILHO, Ataliba Teixeira de, org. A sistematização de arquivos públicos. Campinas : Editora da UNICAMP, 1991. p.63-70

BOtTINO, Mariza. Panorama dos Cursos de Arquivologia no Brasil: graduação e pósgraduação. Arquivo\&Administração, Rio de Janeiro, v.15, n.23, p.12-18, jan./dez. 1994.

CAMARGO, Ana Maria de Almeida. Conservação: os novos arquivos e a formação dos arquivistas. Arquivo: B. Hist. e Inf., São Paulo, v.1, n.10, p.7-9, jan./jun. 1989.

, BELLOTTO, H. L, coord. Dicionário de terminologia arquivística. São Paulo : AAB : SEC/SP, 1996. 142p.

DUCHEIN, Michel. O papel da arquivologia na sociedade de hoje. Arquivo \&Administração, Rio de Janeiro, v.6, n.3, p.30-36, set./dez. 1978.

O respeito aos fundos em Arquivística: princípios teóricos e problemas práticos. Arquivo\&Administração, Rio de Janeiro, v.10-14, n.1, p.14-33, abr./ago. 1986.

MONTEIRO, Norma de Góes. Reflexões sobre o ensino arquivístico no Brasil. Acervo, Rio de Janeiro, v.3, n.2, p.79-89, jul./dez. 1988.

OLIVEIRA, D. A . Memória e ação cultural. Revista do Arquivo Municipal, São Paulo, n.200, p.113-148, 1992.
Mary Stela Muller (Coord.)

Marta Lígia Pomim Valentim

Licéia Cianca Fortes

\section{Claudiomar dos Reis Gonçalves \\ Cristiano Gustavo Biazzo Simon \\ Rosimeire Aparecida Angelini Castro}

\section{Title}

The Undergraduate Program of Archival Science at U.E.L

\section{Abstract}

This is a study about the implantation of the undergraduate program of Archival Science at Universidade Estadual de Londrina (Londrina State University), including a previous research about regional market and clientele. It presents an innovation, which is the partnership of the Department of the Science of Information and the Department of History. The curriculum intends to form professionals with humanistic and technical basis, aiming at the modern professional of information for the 21 st Century. It also includes summaries, objectives, and contents of all the subjects of the program.

\section{Keywords}

Archival Science. Professional of Information. Work Market. Course of Archival Science

Artigo recebido em 15/10/97 


\section{ANEXO 2}

SERIAÇÃO ESTABELECIDA DAS DISCIPLINAS DO CURRÍCULO PLENO DO CURSO DE ARQUIVOLOGIA

\begin{tabular}{|c|c|c|c|c|c|c|c|c|}
\hline \multirow{3}{*}{$\begin{array}{c}\text { SÉRIE } \\
1^{\underline{a}}\end{array}$} & \multirow[b]{2}{*}{ DEP } & \multirow[b]{2}{*}{ NOME DA DISCIPLINA } & \multirow[b]{2}{*}{ TEOR. } & \multirow[b]{2}{*}{ PRAT. } & \multirow[b]{2}{*}{ TOTAL } & \multicolumn{3}{|c|}{ CARGA HORÁRIA } \\
\hline & & & & & & $\begin{array}{c}\text { SEME } \\
10\end{array}$ & $\begin{array}{l}\text { TRAL } \\
2^{\circ}\end{array}$ & ANUAL \\
\hline & $\mathrm{CIN}$ & $\begin{array}{l}\text { Fundamentos da Ciência da Informação e } \\
\text { Arquivologia }\end{array}$ & 68 & & 68 & - & - & Anual \\
\hline $1^{\underline{a}}$ & $\mathrm{CIN}$ & Tipologias documentária & 50 & 18 & 68 & - & - & Anual \\
\hline $1^{\underline{a}}$ & $\mathrm{HIS}$ & História Administrativa do Brasil & 136 & & 136 & - & - & Anual \\
\hline $1^{\underline{a}}$ & $\mathrm{HIS}$ & Arquivo, Memória e Sociedade & 102 & & 102 & - & - & Anual \\
\hline $1^{\underline{a}}$ & PUB & Instituições de Direito Público e Privado & 68 & & 68 & - & - & Anual \\
\hline $1^{\underline{a}}$ & SOC & Sociologia e Informação & 68 & & 68 & - & - & Anual \\
\hline $1^{\underline{a}}$ & $\mathrm{NIC}$ & $\begin{array}{l}\text { Fundamentos de Semiologia/Semiótica } \\
\text { aplicados à Arquivologia }\end{array}$ & 68 & & 68 & - & - & Anual \\
\hline $1^{\underline{a}}$ & LEM & Espanhol Instrumental para a Arquivologia & & 68 & 68 & - & - & Anual \\
\hline $1^{\underline{a}}$ & $\mathrm{HIS}$ & Paleografia e Diplomática & 34 & & 34 & - & $2^{\circ}$ & Sem. \\
\hline
\end{tabular}

\begin{tabular}{|c|c|c|c|c|c|c|c|c|}
\hline SÉRIE & DEP & NOME DA DISCIPLINA & TEOR. & PRAT. & TOTAL & \multicolumn{2}{|c|}{ SEMESTRAL } & ANUAL \\
\hline $2^{\mathrm{a}}$ & $\mathrm{CIN}$ & Análise Documentária I & 34 & 34 & 68 & $y^{-}$ & 2 & Anual \\
\hline $2^{\mathrm{a}}$ & $\mathrm{HIS}$ & Teoria da História & 68 & & 68 & - & - & Anual \\
\hline $2^{a}$ & $\mathrm{CIN}$ & Descrição Documentária & 34 & 68 & 102 & - & - & Anual \\
\hline $2^{\mathrm{a}}$ & $\mathrm{CIN}$ & Arquivos Correntes e Intermediários & 50 & 52 & 102 & - & - & Anual \\
\hline $2^{\mathrm{a}}$ & HIS & História do Paraná & 68 & & 68 & - & - & Anual \\
\hline $2^{\mathrm{a}}$ & PUB & Direito Notarial & 68 & & 68 & - & - & Anual \\
\hline $2^{\mathrm{a}}$ & LEM & Inglês Instrumental para Arquivologia & & 68 & 68 & - & - & Anual \\
\hline $2^{\mathrm{a}}$ & $\mathrm{CIN}$ & Tecnologias Documentárias & 50 & 18 & 68 & - & - & Anual \\
\hline
\end{tabular}

\begin{tabular}{|c|c|c|c|c|c|c|c|c|}
\hline \multirow{3}{*}{$\begin{array}{c}\text { SÉRIE } \\
3^{\text {a }}\end{array}$} & \multirow{3}{*}{$\begin{array}{l}\text { DEP } \\
\text { CIN }\end{array}$} & \multirow[b]{2}{*}{ NOME DA DISCIPLINA } & \multirow{3}{*}{$\begin{array}{r}\text { TEOR. } \\
102\end{array}$} & \multirow{3}{*}{\begin{tabular}{|c|} 
PRAT. \\
34 \\
\end{tabular}} & \multirow[b]{2}{*}{ TOTAL } & \multicolumn{3}{|c|}{ CARGA HORÁRIA } \\
\hline & & & & & & $\begin{array}{l}\text { SEMI } \\
10\end{array}$ & RAL & ANUAL \\
\hline & & Gestão de Arquivos & & & 136 & - & - & Anual \\
\hline $3^{\text {a }}$ & HIS & Historiografia Brasileira & 136 & & 136 & - & - & Anual \\
\hline $3^{\mathrm{a}}$ & $\mathrm{CIN}$ & Análise Documentária II & 34 & 102 & 136 & - & - & Anual \\
\hline $3^{\mathrm{a}}$ & HIS & Arquivos Permanentes & 68 & 34 & 102 & - & - & Anual \\
\hline $3^{\mathrm{a}}$ & CIN & Conservação e Restauração de Documentos & 34 & 68 & 136 & - & - & Anual \\
\hline $3^{\mathrm{a}}$ & $\mathrm{CON}$ & Documentação Contábil & 34 & & 34 & - & $2^{0}$ & Sem. \\
\hline $3^{\mathrm{a}}$ & MAP & Estatística Básica E & 34 & & 34 & $1^{\circ}$ & - & Sem. \\
\hline
\end{tabular}

\begin{tabular}{|c|c|l|c|c|c|c|c|c|}
\hline \multicolumn{4}{|c|}{ SÉRIE } & DEP & \multicolumn{1}{|c}{ NOME DA DISCIPLINA } & TEOR. & PRAT. & \multicolumn{3}{c|}{ TOTAL } & \multicolumn{3}{c|}{ CARMESTRAL HORÁRIA } \\
\hline $4^{\mathrm{a}}$ & HIS & Métodos na Pesquisa Historiográfica & 68 & 34 & 102 & Sem. & - & - \\
\hline $4^{\mathrm{a}}$ & NIC & Comunicação e Difusão em Arquivos & 34 & 34 & 68 & Sem. & - & - \\
\hline $4^{\mathrm{a}}$ & CIN & Documentação Audiovisual & 68 & 34 & 102 & Sem. & - & - \\
\hline $4^{\mathrm{a}}$ & $\begin{array}{c}\text { CIN/ } \\
\text { HIS }\end{array}$ & Tópicos Especiais em Arquivologia & 68 & & 68 & - & Sem. & - \\
\hline $4^{\mathrm{a}}$ & $\begin{array}{c}\text { CIN/ } \\
\text { HIS }\end{array}$ & EST - Arquivologia Aplicada I & & 68 & 68 & Sem. & - & - \\
\hline $4^{\mathrm{a}}$ & $\begin{array}{c}\text { CIN/ } \\
\text { HIS }\end{array}$ & EST - Arquivologia Aplicada II & & 136 & 136 & - & Sem. & - \\
\hline $4^{\mathrm{a}}$ & $\begin{array}{c}\text { CIN/ } \\
\text { HIS }\end{array}$ & EST - Arquivologia Aplicada III & & 68 & 68 & - & Sem. & - \\
\hline
\end{tabular}




\section{ANEXO 3}

\section{EMENTAS / OBJETIVOS / CONTEÚDOS}

\section{CIN - GESTÃO DE ARQUIVOS}

EMENTA: Gestão de Arquivos Públicos e Privados: princípios e funções.

OBJETIVO: Capacitar para a direção, supervisão e coordenação das atividades de um sistema de arquivo.

\section{CONTEÚDO:}

Conceitos básicos de administração e gerência e sua aplicação à arquivos.

Contribuição das diversas teorias e escolas de Administração para a gestão de arquivos.

Desenvolvimento e estrutura organizacional.

Teoria geral de sistemas e sua aplicação na administração e gestão de arquivos.

O arquivo enquanto organização: estrutura e dinâmica organizacional.

Organização, planejamento e administração de arquivos.

Políticas e áreas administrativas: recursos humanos, materiais, financeiros, tecnológicos, físicos e de produção.

Sistema de informação administrativa: fluxos e processos de trabalho; comunicações normativas, relatórios, manuais de serviço.

Processos de Automação nas atividades técnicas e Administrativas de Arquivos.

\section{CIN - TECNOLOGIAS DOCUMENTÁRIAS}

EMENTA: Tecnologias de informação: equipamentos, suportes lógicos, aplicativos e outros utilizados em arquivos públicos e privados.

OBJETIVO: Instrumentalizar para a aplicação dos recursos eletro-óptico-eletrônico utilizados na gestão de documentos.

\section{CONTEÚDO}

Introdução à informática: sistema operacional, softwares aplicativos.

Informática documentária: aplicação dos recursos de processamento de dados.

Microfilmagem de documentos: técnicas, equipamentos, vantagens e desvantagens.

Processamento de imagens: soluções para o arquivamento e gerenciamento de documentos.

Reprografia: técnicas, equipamentos, vantagens e desvantagens.

\section{CIN - CONSERVAÇÃO E RESTAURAÇÃO DE} DOCUMENTOS

EMENTA: Conservação e Restauro de documentos arquivísticos. Política e Programa de Conservação e Restauro.

OBJETIVO: Habilitar para a função arquivística destinada a assegurar as atividades de acondicionamento, armazenamento, preservação e restauração de documentos.

\section{CONTEÚDO:}

Noções teóricas dos princípios gerais de tratamento e conservação de documentos arquivísticos.

A conservação e a restauração.

Agentes causadores da deteriorização dos documentos.

Fatores ambientais na conservação.

Conservação e Restauração de diferentes tipos de suportes de informação.

Conservação e Restauração de documentos históricos e artísticos em papel, couro e pergaminho.

Conservação e Restauração de acervos fotográficos.

Conservação e Restauração de Materiais Especiais: Multimeios.

Políticas e programas de conservação e Restauração.

\section{CIN - FUNDAMENTOS DE CIÊNCIA DA INFORMAČ̃̃O E \\ ARQUIVOLOGIA}

EMENTA: Princípios e Teorias da Ciência da Informação e Arquivologia.

OBJETIVO: Propiciar uma visão panorâmica dos fundamentos teóricos e práticos da Arquivologia.

\section{CONTEÚDO:}

Filosofia e Terminologia da Ciência da Informação e Arquivologia: evolução histórica e conceitual.

A informação como objeto de estudo da Ciência da Informação e da Arquivologia.

Conceito, valor e utilização da informação na sociedade contemporânea.

Conceito, valor e utilização de informação arquivística na sociedade.

Instituições e organismos a serviço da informação: Arquivos, museus e Bibliotecas: diferenças e contrastes.

Tendências profissionais na esfera pública e privada.

Perfil profissional e mercado de trabalho.

Legislação, Conselhos profissionais e órgãos de classe. 


\section{CIN-DESCRIÇÃO DOCUMENTÁRIA}

EMENTA: A representação descritiva e suas aplicações na documentação arquivista.

OBJETIVO: Possibilitar, através de um conjunto de procedimentos, levando em conta os elementos formais de documentos, a CONTEÚDO: elaboração de instrumentos de pesquisa.

A representação descritiva no contexto de arquivologia: Registro Documental.

Representação descritiva de documentos: códigos e normas: arranjos, fundos, grupos e séries.

Entrada de autores individuais e coletivos: normas e padrões.

Títulos informes: entradas e descrição.

Legislação: entradas e descrição.

A compatibilidade de descrição entre os registros documentais e produção documental: manual e automatizado.

Arranjos de coleções de arquivos: norma, forma e sistematização.

\section{CIN/HIS - ARQUIVOS PERMANENTES}

EMENTA: Gestão da documentação permanente em arquivos.

OBJETIVO: Capacitar para o gerenciamento da documentação permanente de arquivos.

\section{CONTEÚDOS:}

Histórico, funções e atividades de destinação.

Administração de arquivos permanentes: arranjo, descrição e produtos.

Arquivos permanentes: terminologia e legislação.

Atividades de referência.

Elaboração de projetos.

\section{CIN - ARQUIVOS CORRENTES E INTERMEDIÁRIOS}

EMENTA: Gestão da documentação corrente e intermediária em arquivos.

OBJETIVO: Capacitar para o gerenciamento da documentação na fase corrente e

\section{CONTEÚDOS:} intermediária.

Princípios fundamentais e práticas arquivísticas: teoria das três idades.

Tabela de Temporalidade.

Administração de arquivo correntes: protocolo, expedição, arquivamento (métodos) e acesso da documentação ativa.

Avaliação e seleção de documentos.

Transferência da documentação ativa.

Arquivos intermediários: histórico, função, vantagens e desvantagens.
Arquivos intermediários: terminologia e legislação.

Administração do arquivo intermediário: tratamento, armazenamento e localização da documentação.

Avaliação e seleção dos documentos.

Elaboração de projetos.

\section{CIN - ANÁLISE DOCUMENTÁRIA II}

EMENTA: Aplicação de teorias de representação e análise documentária.

OBJETIVO: Elaborar instrumentos para o controle, busca, recuperação e disseminação de acervos arquivísticos.

\section{CONTEÚDOS:}

Análise documentária aplicada a resumo e indexação: função e princípios.

Linguagem documentária.

Estrutura e tipologia de resumos documentários.

Metodologia para elaboração de resumos.

Tipologia de índices.

Políticas de indexação.

Metodologias para indexação.

Produtos documentários.

Metodologias para a construção de produtos documentários: tesauro, catálogos impressos, guias impressos, cadastros, bancos e bases de dados e outros.

Elaboração e avaliação de resumos, índices e produtos documentários.

\section{CIN - ANÁLISE DOCUMENTÁRIA I}

EMENTA: Estudo analítico e comparativo das teorias de representação e análise documentária.

OBJETIVO: Habilitar para o reconhecimento de especificidades e elementos temáticos visando o tratamento de acervos documentais específicos.

CONTEÚDOS:

Conceitos genéricos de representação.

Gêneros de representação documentária: representação descritiva, representação temática, representação factual, resumos.

Conceito e função da representação e análise temática.

A representação e análise temática no contexto documentário: fluxo documentário.

Linguagem natural, linguagem de especialidade e linguagens construídas.

A linguagem documentária: especificidades e funções.

Estruturação das linguagens documentárias: relações hierárquicas, relações não hierárquicas e relação de equivalência.

Procedimentos metodológicos de construção e formas de apresentação da linguagem 
documentária.

\section{CIN - TIPOLOGIAS DOCUMENTÁRIA \\ EMENTA: Conceituação, características e classificação da documentação arquivística.}

OBJETIVO: Possibilitar o reconhecimento de diferentes tipos de documentos

CONTEÚDOS: arquivísticos.

Documentação: princípios e conceitos.

Ciclo Documentário.

Gênero documental: textuais, audiovisuais, iconográficos, cartográficos e outros.

Tipologia da documentação arquivística: segundo suas características (forma e conteúdo) e classificação (gênero e natureza).

Instituições e organismos que promovem a documentação: nacionais e internacionais.

Normalização documentária de interesse da área.

Normalização e qualidade: ISO 9000 em sistemas arquivísticos.

\section{PUB - INSTITUIÇÕES DE DIREITO PÚBLICO E PRIVADO}

EMENTA: Instituições de Direito Público e Privado e suas implicações na documentação jurídica.

OBJETIVO: Conhecer as Instituições de direito público e privado enquanto geradora e depositária

CONTEÚDO: de documentação jurídica.

Direito: conceitos, definições, divisão e fontes.

Os ramos do direito.

Direito-teoria; direito-lei; direito-jurisprudência.

Legalidade e legitimidade.

Direito público (sociedade e estado) e Direito privado (personalidade jurídica, obrigação, propriedade e família).

Organização político-administrativa, poderes (divisão orgânica) e níveis de administração (divisão espacial).

Instituições de direito $x$ documentação.

Ética e legislação (...)!! Direito à intimidade. Direito à própria imagem.

\section{CON - DOCUMENTAÇÃO CONTÁBIL}

EMENTA: A contabilidade como fonte geradora de documentos arquivísticos.

OBJETIVO: Conhecer a documentação gerada a partir da contabilidade de organizações

CONTEÚDO: públicas e privadas. programação e controle da atividade empresarial pública e privada.

Métodos e procedimentos contábeis e sua aplicação ao controle econômico-financeiro da empresa/ organização.

Contabilidade: campo de atuação financeiro, especializações, estatística patrimonial: ativo, passivo, patrimônio líquido, equação do patrimônio.

Procedimentos e fatos contábeis: documentos.

Regime de competência de exercício x guarda de documentos.

Documentação financeira: balanços, índices de liquidez, indicadores, etc.

\section{PUB - DIREITO NOTARIAL}

EMENTA: Legislação e administração da documentação de direito público.

OBJETIVO: Conhecer as competências legais da jurisdição arquivística.

\section{CONTEÚDO:}

Conceito e conteúdo do Direito Notarial.

Sistema judiciário brasileiro.

Dos documentos públicos e sua guarda.

Dos registros públicos.

Regime cartorário no Brasil.

Direito notarial comparado (Mercosul).

Sistema de registro em livro.

Arquivamento pelo Poder Público de documentos de interesse privado.

Jurisdição arquivística: competências legais quanto a entrada, custódia, propriedade, transferência, eliminação e recolhimento de arquivos.

\section{LEM - INGLÊS INSTRUMENTAL PARA ARQUIVOLOGIA}

EMENTA: Compreensão de textos/documentos em língua inglesa.

OBJETIVO: Instrumentalizar para a compreensão de CONTEÚDO: textos/documentos em língua inglesa.

Estratégia e compreensão da língua escrita: estudo de textos.

Estratégias de leitura: identificação da idéia geral do tópico frasal, das idéias centrais, das funções comunicativas.

Resumo de textos a partir de idéias de compreensão da língua oral e escrita.

Tradução de textos/documentos de níveis e registros vários.

A contabilidade como fonte de dados para a 
LEM - ESPANHOL INSTRUMENTAL PARA ARQUIVOLOGIA

EMENTA: Compreensão de textos/documentos em língua espanhola.

OBJETIVO: Instrumentalizar para a compreensão de textos/documentos em língua espanhola.

CONTEÚDO:

Estudo das estruturas básicas da língua espanhola: aquisição/ampliação de vocabulário.

Estratégias e compreensão da língua escrita: estudo de textos.

Estratégias de leitura: identificação da idéia geral do tópico frasal, das idéias centrais, das funções comunicativas.

Resumo de textos a partir de idéias de compreensão da língua oral e escrita.

Tradução de textos/documentos de níveis e registros vários.

PSI - PSICOLOGIA APLICADA À ARQUIVOLOGIA

EMENTA: A dinâmica das relações humanas e de trabalho em sistemas arquivísticos.

OBJETIVO: Conscientizar para a importância e necessidade da psicologia para a eficiência profissional.

CONTEÚDO:

Delimitação do campo da psicologia aplicada à administração/gestão de arquivos.

As relações humanas e a psicologia.

O homem e o meio x personalidade e organização.

Principais fenômenos de grupo.

Processos de grupo e relações interpessoais.

Comunicação nas relações humanas e de trabalho.

Mecanismos de defesa do grupo.

As relações humanas no trabalho: cooperação $\mathrm{x}$ competição.

\section{SOC - SOCIOLOGIA DA INFORMAÇÃO}

EMENTA: Informação e processo de desenvolvimento social: fundamentos sociológicos.

OBJETIVO: Entender a informação como setor estratégico e propulsor da sociedade.

Discutir as relações entre informação e mudança social.

\section{CONTEÚDO:}

Sociologia, cultura e sociedade.

Socialização e comunicação simbólica.

O desenvolvimento social: processos sociais, coesão e disjunção.

Relações de poder da sociedade.

Mudança social e mudança cultural: o papel da informação.

Sociologia, Informação e Sociedade.
- sociedade industrial

- sociedade pós-moderna

- sociedade da informação

Impactos sociais das tecnologias da informação.

Impactos sociais da globalização.

Informação $x$ setor quaternário $x$ desenvolvimento sócio-econômico.

Sociedade do Futuro x memória: o papel do arquivo.

\section{CIN - DOCUMENTAÇÃO AUDIOVISUAL}

EMENTA: Gerenciamento e tratamento documentário de materiais audiovisuais.

OBJETIVO: Preparar para a organização, tratamento e gestão de documentos audiovisuais em sistemas arquivísticos.

\section{CONTEÚDO:}

Os audiovisuais como documentos comuns à arquivologia, biblioteconomia/documentação e museologia.

A leitura de documentos audiovisuais.

A diversidade de suporte e sua contínua renovação.

Análise e representação documentária, de documentos sonoros contendo entrevistas, reportagens, depoimentos, etc.

Análise e representação de documentos iconográficos.

Análise e representação de documentos filmícos.

Organização, gestão, arranjo e conservação de documentos audiovisuais em sistemas arquivísticos.

Elaboração de projeto.

NIC - FUNDAMENTOS DE SEMIOLOGIA/ SEMIÓTICA APLICADO A ARQUIVOLOGIA

EMENTA: Introdução ao estudo dos signos e a semiologia/semiótica.

OBJETIVO: Instrumentalizar para a leitura da documentação arquivística.

CONTEÚDO:

Teoria semiológica/teoria semiótica: conceitos fundamentais.

Semiologia/semiótica e as ciências da informação.

Objetos e campo da semiologia/semiótica.

Construções teóricas da pesquisa semiótica.

Signos: definições, classificações, características e funções.

Semiologia/semiótica como instrumento "leitura" da documentação arquivística.

NIC - COMUNICAÇÃO, DIVULGAÇÃO E DIFUSÃO EM ARQUIVOS

EMENTA: Comunicação, divulgação e difusão dos 
serviços e produtos de sistemas arquivísticos.

OBJETIVO: Conhecer os conceitos, os aspectos gerais da atividade de Relações Públicas, e sua aplicabilidade na divulgação e difusão dos ,produtos e serviços de um arquivo.

\section{CONTEÚDO:}

Fundamentos de Comunicação, Opinião Pública e Relações Públicas.

Arquivos e a Questão da Responsabilidade Social.

Conceito de Comportamento Coletivo: Massa e Público.

Definição e Classificação dos Públicos dos diferentes tipos de Arquivo.

Pesquisa das Necessidades dos Públicos.

Tecnologia Básica de Relações Públicas aplicada em Arquivos.

Os produtos e Serviços de um Arquivo Público e/ou Privado.

Comunicação, Divulgação e Difusão dos Serviços e Produtos de um Arquivo.

Avaliação, Revisão e Adaptação das Estruturas Internas

Objetivos e Estratégias de Comunicação com os Públicos.

Processos de Relacionamento para os Diferentes Públicos.

Levantamento dos Veículos de Comunicação Disponíveis

Planejamento de Programas de Comunicação e Informação

Implantação, Avaliação e Controle.

\section{HIS - TEORIA DA HISTÓRIA}

EMENTA: Perspectivas da teoria da história do ponto de vista da utilização de fontes e arquivos. Controvérsia entre os documentos escritos e os documentos em suportes nãoconvencionais.

\section{OBJETIVOS:}

1- Compreender a determinação do fato por via documental: a crítica de procedência.

2- Observar, na Escola de Annalles, o caráter da chamada "revolução documental": documento e série, documentos não escritos, monumentos $x$ documentos.

3- Observar o tratamento conferido à documentação pela história cultural: o documento como signo e o problema da suplementaridade.

\section{CONTEÚDOS:}

O Positivismo e a crítica de procedência.

A Escola dos Annalles: revolução documental.

História cultural: hermenêutica e documento.
HIS - PALEOGRAFIA E DIPLOMÁTICA

EMENTA: Paleografia e Diplomática como suporte

\section{OBJETIVOS:}

para a Arquivologia.

1- Compreender a evolução da paleografia relacionando-a com outras áreas de conhecimento.

2- Capacitar o aluno a resolver as dificuldades na leitura de textos.

3- Fornecer subsídios para a compreensão dos aspectos gráficos, materiais e complementares dos documentos.

4- Identificar os elementos que compõem os documentos.

5- Aplicar conhecimentos diplomáticos à documentação arquivística.

6- Conhecer e aplicar as normas de transcrição paleográfica.

\section{CONTEÚDOS:}

Conceitos, métodos e técnicas de paleografia.

Características do documento paleográfico.

Normas técnicas de leitura e transcrição dos documentos.

A diplomática e os arquivos.

\section{HIS-MÉTODOS NA PESQUISA HISTORIOGRÁFICA}

EMENTA: A relação entre a historiografia e a erudição, principalmente quanto à crítica das fontes históricas, em uma perspectiva diacrônica. Elaboração de projeto de pesquisa.

\section{OBJETIVOS:}

1- Fornecer uma visão diacrônica da tradição erudita relacionada com a historiografia.

2- Observar a proximidade entre a crítica historiográfica renascentista e a exegese dos textos sagrados.

3- Entender de que maneira crítica romântica propunha uma concepção hermenêutica do documento.

4- Explicar de que modo, para a crítica positivista, o documento e o fato se superpõem.

5- Apresentar o problema da crítica documental relacionando-a com a informática; o dado e a informação.

\section{CONTEÚDOS:}

Estudo da erudição voltado para o tratamento de documentos históricos.

Humanismo italiano e fontes documentais.

Erudição e documento.

Documento e crítica romântica (idéia de nação).

Documento e crítica positivista (fato). 


\section{HIS - HISTORIOGRAFIA BRASILEIRA}

EMENTA: A crônica colonial. Historiografia brasileira nos séculos XIX e XX.

\section{OBJETIVOS:}

1- Situar-se no debate historiográfico acerca da colonização do Brasil.

2- Refletir sobre a produção historiográfica brasileira acerca do Império e da República.

3- Estabelecer a relação entre a documentação produzida nos referidos períodos e as interpretações historiográficas.

\section{CONTEÚDOS:}

Reflexões historiográficas.

A crônica colonial.

A produção historiográfica enquanto resgate para a construção da idéia de "nação".

A produção historiográfica brasileira no século XX.

\section{HIS - ARQUIVO, MEMÓRIA E SOCIEDADE}

EMENTA: Arquivo, Memória e Sociedade na construção do conhecimento histórico e arquivístico.

\section{OBJETIVOS:}

1- Relacionar arquivo, memória e história na construção do conhecimento histórico e arquivístico.

2- Reconhecer a importância da preservação e organização documental para a memória, e, conseqüentemente, para a identidade individual e coletiva das sociedades.

3- Compreender o movimento de constituição de arquivos privados e públicos e sua relação política com a memória das instituições e dos grupos sociais.

4- Situar-se no debate historiográfico a respeito do patrimônio cultural, cidadania e de políticas públicas de preservação da memória social.

\section{CONTEÚDOS:}

Conceitos de memória em diferentes temporalidades: da oralidade à contemporaneidade.

Os materiais da memória coletiva e da história: documento e monumento.

Políticas públicas para a memória e arquivos.

Patrimônio cultural, preservação e cidadania.

\section{HIS - HISTÓRIA ADMINISTRATIVA DO BRASIL}

EMENTA: Administração Colonial. 0 público e o privado na administração brasileira nos séculos XIXe XX.

\section{OBJETIVOS:}

1- Compreender as relações entre o historiador, as fontes e os arquivos institucionais brasileiros.

2- Conhecer a estrutura administrativa do sistema colonial.

3- Compreender como se institucionalizou as relações entre público e privado na sociedade brasileira.

CONTEÚDOS:

Administração colonial.

A organização do Estado Imperial: Legislação, administração e instituições civis.

O público e o privado na administração brasileira nos séculos XIXeXX.

\section{HIS - ARQUIVOS PERMANENTES}

EMENTA: Gestão e Difusão de arquivos permanentes.

OBJETIVOS:

1- Capacitar o aluno a gerir arquivos permanentes.

2- Desenvolver a capacidade de reconhecer e avaliar o valor dos documentos da terceira idade, a partir do bom senso para o trabalho arquivístico.

3- Situar-se no debate historiográfico relativo à memória e à preservação.

\section{CONTEÚDOS:}

Gestão de Arquivos Permanentes;

Identificação, Arranjo e Descrição dos Documentos de caráter permanente;

Elaboração de Instrumentos de pesquisa: Catálogos, Índices, Guias de acervo, repertórios, Edição de textos, Inventários;

Difusão Cultural;

Legislação para Arquivos Públicos e Privados;

Elaboração de Projetos.

Ética para trabalhos com diferentes suportes documentais (acervos orais, fotográficos, jurídicos).

\section{CIN/HIS - ARQUIVOLOGIA APLICADA III}

EMENTA: Elaboração de monografia aplicando de forma integrada os conhecimentos teóricos e práticos adquiridos durante o curso.

OBJETIVO: Despertar para a conscientização crítica e reflexiva da realidade profissional.

\section{CONTEÚDO:}

Tópicos de livre escolha, próprios da área, devendo resultar em trabalho de pesquisa ou memorial descritivo da ação implementada.

\section{CIN/HIS - ARQUIVOLOGIA APLICADA II}

EMENTA: Desenvolvimento de atividades relacionadas a organização/gestão de arquivos públicos e privados.

OBJETIVO: Capacitar para a organização e gerenciamento de sistemas arquivísticos.

\section{CONTEÚDO:}

Execução de atividades centradas no cliente, relacionadas a organização/gestão e funcionamento de diferentes tipos de arquivos.

\section{CIN/HIS - ARQUIVOLOGIA APLICADA I}

EMENTA: Observação, análise e relato de atividades desenvolvidas em Arquivos públicos e privados.

OBJETIVO: Despertar para o fazer e o viver profissional do arquivista.

Fontes para a História do Norte do Paraná.

Arquivos, Museus e outras instituições de guarda e preservação da memória paranaense.

Produção da História do Paraná. 


\section{MAP- ESTATÍSTICA BÁSICA E}

EMENTA: Estatística Básica Aplicada à Arquivologia

OBJETIVO: Instrumentalizar para a compreensão e uso de estatística em geral.

\section{CONTEÚDO:}

Estudo das estruturas básicas de estatística.

Estratégias para compreensão e uso da estatística aplicada à arquivologia. 